\title{
Clinical and Endoscopic Characteristics of Chinese Cronkhite-Canada Syndrome Patients: A Retrospective Study of 103 cases
}

\section{Yuanyuan Lu}

Wuhan University Zhongnan Hospital

\section{Fengxing Huang}

Wuhan University Zhongnan Hospital

\section{Youwei Wang}

Wuhan University Zhongnan Hospital

\section{Juan Zhou}

Wuhan University Zhongnan Hospital

\section{Qiu Zhao}

Wuhan University Zhongnan Hospital

Lan Liu ( $\nabla$ lliugi@whu.edu.cn )

Wuhan University Zhongnan Hospital

\section{Research article}

Keywords: Cronkhite-Canada syndrome, Clinical characteristics, Endoscopy

Posted Date: August 6th, 2020

DOl: https://doi.org/10.21203/rs.3.rs-47967/v1

License: (c) (1) This work is licensed under a Creative Commons Attribution 4.0 International License. Read Full License 


\section{Abstract}

Background: Cronkhite-Canada syndrome (CCS) is a rare non-inherited disease characterized by extensive gastrointestinal polyposis and ectodermal dysplasia. Its etiology still remains indefinite to us. Currently, the diagnosis is mainly based on typical clinical manifestations and endoscopic features. However, there is a lack of these information from Chinese CCS patients. Our study was to investigate the clinical and endoscopic characteristics of Chinese CCS patients.

Methods: This retrospective study was conducted in 103 Chinese CCS patients (102 cases from literature and 1 case from our department). Their clinical and endoscopic data were collected, and statistical analyses were performed.

Results: 1) In Chinese population, people aged $50-70$ years $(62.62 \%)$ had a high incidence of CCS, and the ratio of male-to-female was 2.68:1. 2) The diverse range of gastrointestinal (GI) manifestations were observed in all the patients, and the most common symptoms were weight loss (98.80\%) and loss of appetite (93.94\%). Almost all the patients had at least one symptom of ectodermal dysplasias. 3) All CCS patients presented multiple polyps in the GI tract except esophagus. The size of polyps varied from 0.5 $\mathrm{cm}(88.64 \%)$ to $0.6-1.0 \mathrm{~cm}(81.82 \%)$. The polyps were various in shapes, the most of them were nodular polyps $(58.14 \%)$, what's more,the sessile polyps were the most common(90.24\%). Congestion, edema and erosion were very common on the surface of polyps (96.83\%) and the surrounding mucosa (85.71\%) . 4) The common pathological features of polyps were hyperplastic polyps (49.25\%) and tubular adenomatous polyps (44.78\%). There is only $5.97 \%$ cancer reported.

Conclusions: middle-aged and elderly people are the high-risk group; various gastrointestinal symptoms are observed in Chinese patients; the typical endoscopic finding is multiple small sessile polyps; these gastrointestinal polyps has a chance of malignant potential. Long-term endoscopic surveillance and follow-up are recommended for the CCS patients in China.

\section{Background}

Cronkhite-Canada syndrome (CCS), also known as a multiple gastrointestinal polyps-hyperpigmentationalopecia-onychodystrophy syndrome, is first reported by Cronkhite and Canada in 1955 [1]. CCS is a very rare non-inherited disease. The highest incidence of CCS is reported in Japan as approximately $0.00037 / 100$ [2]. Up to date, there are over 500 cases all over the world. The pathogenesis of CCS still remains unclear. Most scholars believe that CCS is an autoimmune-related disease, especially closely related to $\lg \mathrm{G} 4[3,4]$.

Gastrointestinal (GI) disorder and ectodermal dysplasia are the most common symptoms presented in CCS patients. Usually, at least one ectodermal dysplasia symptom is shown in CCS patient such as alopecia, onychodystrophy and skin hyperpigmentation. A wild range of Gl symptoms is observed including abdominal pain, diarrhea, hypogeusia and weight loss as the initial symptom. According to the initial symptoms, patients could be divided into 5 types: diarrhea (type1), hypogeusia (type2), xerostomia 
or a strange sensation in oral cavity (type3), abdominal pain (type4) and alopecia (type5) [5]. Endoscopic examination is the most important in all of the auxiliary examinations. It is manifested as diffuse multiple polyps in the GI tract, most of which are sessile polyps with various shapes. Currently, CCS diagnosis is mainly relied on typical clinical manifestations and endoscopic findings. At present, there is no effective specific treatment for CCS. The most used approaches include symptomatic remission, nutritional therapy and corticosteroid. The prognosis of CCS is very poor, 5 -year survival rate is less than $45 \%[6]$.

So far, the majority of CCS related literature are published as single case report or reviewed with limited case numbers. The study with the maximum number is 210 cases from Japan [7]. It mainly explored the best potential of treatment and monitoring strategies by evaluating the treatment efficacy of endoscopy and other approaches. As for Chinese CCS patients, The most recent literature in international journal was published in 2013 with limited cases (49 Chinese CCS patients) [8]. It summarized the clinical characteristics of CCS patients to better understand CCS in China. Up to date, there is still very little description and analysis of CCS's features, especially the specific endoscopic findings in Chinese patients. Our study is to review all the documented Chinese CCS cases so far, and update the clinical and endoscopic manifestations in Chinese patients.

\section{Methods}

A literature search of the CBM Web (year range:1978-2020.03), WanFang Data (1989-2020.03) and PubMed (1950-2020.03) was performed to identify publications with "Cronkhite-Canada" or "CronkhiteCanada case report" in the title or abstract. Inclusion criteria: all patients were Chinese and had complete endoscopic reports; Exclusion criteria: confirmed duplicate cases, suspected duplicate cases and cases with the missing of endoscopic results. All identified cases were collected. 102 cases were reported in the literature, and one un-published case from our department was added. Thus, this retrospective study encompasses a total of 103 patients.

The SPSS24.0 software was utilized for statistical analyses. The $\chi^{2}$ test was used to calculate the statistical significance between groups. If the theoretical frequency was less than 1 , or $1 \leq$ theoretical frequency $<5$ in RxC table was more than $1 / 5$ of the total numbers, statistical significance was determined with the Fisher's exact test. $P$ values lower than 0.05 were considered statistically significant.

\section{Results}

\section{1) Sex and age distribution}

Of 103 Chinese CCS patients, 75 were men and 28 were women, which yielded a male-to-female ratio of 2.68:1 (Fig. 1a). The age range of patients was from 9 to 82 years old, and the majority of groups were between 50 to 60 years old(30.30\%)and 60 to 70 years old (32.32\%). The average age was 57.39 years old (Fig. 1b). 


\section{2) Clinical manifestations}

GI discomfort was the initial symptom and the reason of seeking for medical treatment for most CCS patients. The most common symptoms were weight loss $(98.80 \%, 82 / 83)$ and loss of appetite $(93.94 \%$, $62 / 66)$. Abdominal pain and diarrhea accounted for $69.57 \%$ (48/69), 88.78\% (87/98), respectively. Although location and nature of abdominal pain were diverse, the hidden pain of umbilical region was predominant. Usually, the diarrhea accompanied the change in stool, which was lose $(40.74 \%, 33 / 81)$ or watery $(41.98 \%, 34 / 81)$. And some patients even had bloody stool $(37.04 \%, 30 / 81)$. Other common symptoms were hypogeusia (34/43) and edema (38/59) (Fig. 2a). The edema was often observed in lower limbs (33/38). Patients could lose $10 \mathrm{~kg}$ a month in some severe cases.

Almost all the patients had at least one symptom of ectodermal dysplasia: alopecia (91/95), hyperpigmentation (90/94) and Onychodystrophy (101/101) (Fig. 2b). Scalp hair loss occurred first, and followed by the loss of eyebrows, eyelashes and the hair of limbs. Different size of tan spots was distributed on the palms, soles, face, neck, limbs and oral with a clear boundary. Nails are characterized by tarnish, brittle and cracking. Some patients had completely chipped nails.

\section{3) Laboratory examinations}

A peripheral blood test mainly showed anemia and low serum protein. Decreased hemoglobin was shown in 38 patients. Most of them were mild and moderate anemia, and only 2 patients were severe anemia with $<30 \mathrm{~g} / \mathrm{L}$ hemoglobin. Other indexes of routine blood test were not significantly abnormal. Serum total proteins were low in 55 of 63 patients and serum albumin levels were low in 72 of 84 patients, which indicate malnutrition in lots patients. Among the 76 patients with fecal test records, $77.63 \%(59 / 76)$ of them had positive in occult blood (OB) test. Only 24 patients had results of Helicobacter pylori (HP) test, 3 of them was positive (Fig. 2c).

\section{4) Endoscopy and pathology}

All 103 patients underwent esophagogastroduodenal endoscopy and/or colonoscopy, However, the author only presented the result that they considered important, the effective number of cases for endoscopic features was not all 103. All the endoscopic features were summarized in Table 1. 
Table 1

Endoscopic characteritics of Chinese Cronkhite-Canada Syndrome (CCS ) patients

\section{Endoscopic Characteritics}

\section{Size}

$\leq 0.5 \mathrm{~cm}$

$0.6-1.0 \mathrm{~cm}$

$1.1-2.0 \mathrm{~cm}$

$>2.0 \mathrm{~cm}$

Shape

Nodular

Lobulated

Strawberry-like

Coral-like

Cauliflower-like

Granular

Grape-like

Herpes-like

Beads-like

Circular

Hemispherical

The effective number of cases describing the size, shape, surrounding mucosal lesion, basement and surface of polyps was $44,43,49,41,63$, respectively.A patient could have multiple lesions at the same time.

\section{Surrounding mucosal lesion}

Smooth $\quad 5$

Reddish,congestion,edema and erosion $\quad 42$

Pale 2

Pigmentation 4

\section{Basement}

Pedicle

19

Sub-pedicle

14

Sessile

37

1

$1 \quad$ Surface

Smooth

5

Reddish,engorged,edema and erosion

61

Strawberry-like change

1

Lobulated change

2

Spotted change

1

Cauliflower-like change

\section{a. Location}

The polyps could be found all over the digestive track: $92.23 \%(95 / 103)$ in stomach, $73.79 \%(76 / 103)$ in small intestine, $94.17 \%(97 / 103)$ in colon and rectum. They were mainly located in gastric antrum $(36 / 103)$ and duodenal bulb (39/103). The esophagus was rarely involved (4/103) ( Table 1$)$.

b. Size

44 of 103 patients had the detailed information about polyps' size. The size was varied from $\leq 0.5 \mathrm{~cm}$ to $>2.0 \mathrm{~cm}$. By comparing polyps among stomach, small intestine, colon and rectum, the whole $\mathrm{Gl}$ tract was 
dominated by small polyps with diameters $\leq 0.5 \mathrm{~cm}$ (88.64\%). The polyps $>2.0 \mathrm{~cm}$ was mentioned in 16 patients. There was no statistically significant difference in size of polyps in comparison of various parts of $\mathrm{Gl} \operatorname{tract}(P=0.794>0.05)$ (Table 1$)$.

\section{c. Basement}

Of 103 patients, 41 had the description of basement features. Pedicle, sub-pedicle and sessile polyps were accounted for $46.34 \%, 34.15 \%$ and $90.24 \%$ respectively. In comparison of stomach, small intestine, colon and rectum, there was no statistically significant difference in basement feature of polyps $(P=$ $0.559>0.05)$ (Table 1).

\section{d. Shape}

The polyps were various in shapes according to the 43 patients. 11 different morphologies of polyps were described in total: nodular, lobulated, strawberry-like, coral-like, cauliflower-like, granular, grape-like, herpes-like, beads-like, circular and hemispherical. Nodular polyps (25/43) were the most common, and other shapes were scattered. there was no statistically significant difference in the shape of polyps located in different parts of $\mathrm{Gl}$ tract $(P=0.749>0.05)$ (Table 1$)$.

\section{e. Surface}

According the records from 63 patients, the polyps surface was presented a variety of feature such as smooth; reddish, engorged, edema and erosion; strawberry-like change; lobulated change; spotted change and cauliflower-like change. Reddish, engorged, edema and erosion were the most common observed in 61 patients $(61 / 63)$. There was also no statistically significant difference in the feature of polyps' surface in different parts of $\mathrm{Gl}$ tract $(P=0.764>0.05)$ (Table 1$)$.

\section{f. Surrounding mucosal lesion}

In order to better understand the characteristics of CCS, we further investigated the surrounding mucosa of polyps. Its detailed description was found in 49 of 103 cases. The surrounding mucosa could be smooth; reddish, congestion, edema and erosion; pale and pigmentation under the endoscopy. Reddish, congestion, edema and erosion in adjacent mucosa were observed in almost 42 (85.71\%) patients. Only 5 patients reported smooth. The different levels of inflammation were observed in nearly all the mucosa surrounded polyps. And no statistically significant difference found in mucosal lesions $(P=0.199>0.05)$ (Table 1).

\section{g. Pathology}

Neoplastic and nonneoplastic polyps were both visible in CCS patients, $5.97 \%$ of the patients were cancerous (4/67). Hyperplastic polyps and tubular adenoma were the most common ones, accounting for $49.25 \%$ and $44.78 \%$ respectively. Furthermore, hyperplastic polyps were most common in the stomach $(19 / 33)$ and tubular adenomas were most common in the colon (17/30) (Fig. 3). 


\section{5) Treatment and prognosis}

Medical treatments reported in the literature vary. Some patients may use one or more of these treatments, and almost every patient was given symptomatic remission and nutritional support treatment. 50 patients $(51.02 \%)$ received corticosteroid, which was used the most. Based on the view of some scholars that CCS was an immune disease, 3 patients $(3.06 \%)$ were specially treated with immunomodulators. Other treatments were antibiotic (23/98), non-steroidal anti-inflammatory drugs (NSAIDs)(20/98), acid inhibitor (27/98), Chinese herbal medicines (15/98), therapeutic endoscopy (29/98), surgery (9/98).

The follow-up data were available in 68 of the 103 CCS patients. 12 patients (17.65\%) died of the disease, 2 patients $(2.94 \%)$ showed deterioration, 2 patients $(2.94 \%)$ had no remission, 4 patients $(5.88 \%)$ had recurrence after discharge, and 45 patients $(66.18 \%)$ had an improvement in symptoms.

\section{Discussion}

CCS is a rare disease characterized with generalized gastrointestinal polyps and ectodermal dysplasia. The etiology and pathogenesis are not clear. There is no effective treatment available now. In this study, we reviewed clinical information from all documented Chinese CCS patients so far, especially the detailed description of endoscopic characteristics, so as to update and better understand CCS in China patients.

Our data has revealed that people aged 50-70 years had a high incidence of CCS in China, and most of them were male (72.82\%). The previous study with largest sample size has reported that males between 50 and 70 years old were the high risk group [5], and the most recent nationwide survey from Japan has also shown that the ration of male to female was 248:225 [2]. Our findings from Chinese CCS patients were very similar with those results from other areas. We also noticed that Beijing was the city where the most patients were located in compared with other places in China(26/103). However, the location in patient record usually was the place patients received the treatment. Since the healthcare system in Beijing is much stronger than most area of China, lots of patients from other places would come to Beijing for medical treatment. Therefore, this result of location statistics is still open to question.

CCS is believed to be a non-genetic disease. Till now, only two family cases have been reported $[9,10]$. The pathogenesis of CCS is still unclear. Many researchers believed that CCS was an autoimmune disease because that IgG4-positive cell infiltration was observed and hormone therapy was effective in some cases $[3,4,11]$. However, the study from Li et al. [12] shown that CCS was not the variant of IgG4related disease, although the IgG4-positive plasma cells might be involved in CCS pathogenesis. A study stated that CCS might be related to allergies [13]. In addition, Goto et al. [5] reported that mental stress and physical fatigue were the important risk factors for CCS. HP might also another factor since eradication of HP could reduce some symptoms in CCS patients $[14,15]$. There is very limited information in our study. Only 2 patients had IgG4 plasma cells positive in polyps detected by immunohistochemistry. And 3 out of 24 patients was HP test positive. Further investigations are needed to address these questions throughout. 
Gastrointestinal disorder is the major clinical manifestations of CCS, which is also the initial symptom of most patients. The similar GI symptoms were observed in all 103 Chinese patients including abdominal pain, diarrhea and so on. Besides, hypogeusia was found in some patients. Some studies have shown that hypogeusia could be caused by inflammation, infection or other oral mucosa lesion. The deficiency of zinc and copper could also lead to hypogeusia [16]. Serum electrolyte disturbances is very common in CCS patients due to malabsorption and appetite loss [8]. However, we didn't get enough data to confirm the connection between hypogeusia and electrolyte disturbances in current study. Ectodermal dysplasia is the other major clinical manifestations of CCS. Almost all patients in our study presented with at least one symptom of ectodermal dysplasia such as hair loss and nail change. The underlying mechanism is still unknown. Hair loss might be caused by malabsorption [17], but Horikawa et al. [18] has proposed that it was at least partly due to the autoimmuntiy, and Chuamanochan et al. [19] has reported that nail change in CCS patients was the result from inflammatory response, not only the malnutrition.

Previous studies have shown that polyps in CCS patients were diffusely distributed throughout the entire alimentary tract except esophagus [6,8]. In our study, Polyps were observed along the gastrointestinal tract by endoscopy, and only 4 patients had polyps in esophagus. Most polyps were sessile and less than $1.0 \mathrm{~cm}$. The appearance of polyps was various, nodule-like shape was the most observed. The surface of polyps and surrounding mucosa were presented with reddish, engorged, edema or erosion in all the patients. These endoscopy findings could help to better distinguish CCS from a number of polyposis syndromes such as familial adenomatous polyposis, Gardner syndrome, Turcot syndrome, Peutz-Jeghers syndrome, Juvenile polyposis syndrome and Cowden syndrome.

Initially, CCS had been considered to be a hamartomatous polyposis syndrome [16]. But it has been realized that the polyps of CCS could be inflammatory, adenomatous and hyperplastic now. Based on the study of 14 consecutive CCS patients registered at the Mayo Clinic, the incidence of adenomatous polyps had reached $71 \%$ [4]. Our data shown that hyperplastic polyps and tubular adenomas were the most common polyps in Chinese CCS patients, and adenomatous polyps account for $22.39 \%$. The reason for this difference needs to be investigated and researched by a larger sample size. Yashiro et al. [20] have confirmed that genetic changes linking sawtooth adenoma to colorectal cancer, and proposed a serrated adenoma-carcinoma sequence in CCS. The data from Haghighi et al. [21] has reported that the incidence of cancer in CCS was $15.6 \%$ (78/500). It is still controversial whether cancer is a coincidence in CCS patients or developed from benign polyps. In general, the overall risk of cancer in CCS is 5-25\% [22-24]. Our study has found that the prevalence of cancer was $5.97 \%$ in Chinese CCS patients. This rate in Chinese patients is much lower than others in the world. But it is higher than the national cancer incidence rate of $0.2781 \%$ announced by National Central Cancer Registry of China (NCCRC) in 2014 [25]. Therefore, long-term endoscopic surveillance and follow-up are recommended for Chinese CCS patients.

Because of the unclarified etiology of CCS, there is no consensus on the CCS management. At present, the treatment includes symptomatic remission and nutritional therapy, corticosteroid,antibiotic, NSAIDs, acid inhibitor, immunomodulator, Chinese herbal medicines, therapeutic endoscopy and surgery. Study has reported that corticosteroid and immunomodulator were the most effective treatment so fat, which 
could maintain clinical remission for more than 8 years [26-28]. In our study,almost every patient was given symptomatic remission and nutritional therapy. 50 patients $(51.02 \%)$ received corticosteroids. A total of 68 patients were followed up, $12(17.65 \%)$ patients had died of the disease, $45(66.18 \%)$ patients had remission. The cause of death is mainly the disease itself or the complications: severe cachexia, congestive heart failure, embolism, sepsis, and shock. Compared to the previously reported $55 \%$ mortality rate for CCS, The prognosis of CCS is much better than before.

This retrospective study is with the largest case number including all the documented Chinese CCS patients so far. However, there are still some limitations to this study. All the data were collected from the case report, some of the data was incomplete, especially the laboratory test, pathology and prognosis. The scarcity of cases limits the understanding of the disease. It will be improved by the future investigation.

\section{Conclusions}

The polyps in Chinses CCS patients are multiple small polyps along GI tract, and they are various on shape. And it usually accompanied by hyperemia, edema and erosion on the surface of polyps and surrounding mucosa. There is no significant difference in characteristics of polyps under endoscopy between Chinese and foreign CCS patients. There is a chance of malignant potential for Chinese CCS patients, long-term endoscopic surveillance and follow-up are recommended.

\section{List Of Abbreviations}

CCS: Cronkhite-Canada syndrome ;

Gl: Gastrointestinal;

HP: Helicobacter pylori;

NSAIDs: Non-steroidal anti-inflammatory drugs;

OB: Occult blood.

\section{Declarations}

\section{Ethics approval and consent for publication}

Our study protocol complied with the ethical guidelines of the Declaration of Helsinki and was approved by the institutional ethics committee of Zhongnan Hospital of Wuhan University (No. 2020065K), and waiver of informed consent was approved as the bulk data was received and analyzed anonymously.

\section{Availability of data and materials}


Not applicable.

\section{Competing interests}

All authors have no conflicts of interest to declare.

\section{Funding}

All authors didn't receive any funding.

\section{Authors' Contributions}

Lan Liu and Qiu Zhao contributed to the design of the study, and supervised the whole study process; Fengxing Huang, Youwei Wang, and Yuanyuan Lu and Juan Zhou collected and analyzed data; Yuanyuan Lu performed the statistical analysis and drafted the manuscript; Lan Liu critically reviewed the manuscript. All authors have substantially contributed to and agree on the content of the manuscript.

\section{Acknowledgements}

Not applicable.

\section{References}

1. Cronkhite Jr LW, Canada WJ. Generalized gastrointestinal polyposis: an unusual syndrome of polyposis, pigmentation, alopecia and onychotrophia. N Engl J Med. 1955;252:1011-5.

2. Oba MS, Murakami Y, Nishiwaki Y, Asakura K, Ohfuji S, Fukushima W, et al. Estimated prevalence of Cronkhite-Canada Syndrome, Chronic Enteropathy Associated with SLCO2A1 Gene, and Intestinal Behcet's Disease in Japan in 2017:A Nationwide Survey. J Epidemiol. 2020; doi: 10.2188/jea.JE20190349.

3. Fan RY, Wang XW, Xue LJ, An R,Sheng JQ. Cronkhite-Canada syndrome polyps infiltrated with IgG4positive plasma cells. World J Clin cases. 2016;4:248-52.

4. Sweetser S, Ahlquist DA, Osborn NK, Sanderson SO, Smyrk TC, Chari ST, et al. Clinical pathologic features and treatment outcomes in Cronkhite-Canada syndrome:support for autoimmunity. Dig Dis Sci. 2012;57:496-502.

5. Akihiko G. Cronkhite-Canada syndrome:epidemiological study of 110 cases reported in Japan. Arch Jpn Chir. 1995;64:3-14.

6. Daniel ES, Ludwig SL, Lewin KJ, Ruprecht RM, Rajacich GM, Schwabe AD. The Cronkhite-Canada Syndrome: An analysis of clinical and pathologic features and therapy in 55 patients. Medicine. 1982;61:293-309.

7. Watanabe C, Komoto S, Tomita K, Hokari R, Tanaka M, Hirata I, et al. Endoscopic and clinical evaluation of treatment and prognosis of Cronkhite-Canada syndrome: a Japanese nationwide survey. J Gastroenterol. 2016;51:327-36. 
8. She Q, Jiang JX, Si XM, Tian XY, Shi RH, Zhang GX. A severe course of Cronkhite-Canada syndrome and the review of clinical features and therapy in 49 Chinese patients. Turk J Gastroenterol. 2013;24:277-85.

9. Pati V, Patil LS, Jakareddy R, Verma A, Gupta AB. Cronkhite-Canada syndrome: a report of two familial cases. Indian J Gastroenterol. 2013;32:119-22.

10. Wang JY, Lu WQ, Ning HB. Clinical analysis of Cronkhite-Canada syndrome(in Chinese). Henan Medical Research. 2019;28:1931-5.

11. Murata I, Yoshikawa I, Endo M, Tai M, Toyoda C, Abe S, et al. Cronkhite-Canada syndrome: report of two cases. J Gastroenterol. 2000;35:706-11.

12. Li Y, Luo HQ, Wu D, Xue XW, Luo YF, Xiao YM, et al. Clinicopathologic features of Cronkhite-Canada syndrome and the significance of IgG4-positive plasma cells infiltration. Chin J Pathol. 2018;47:7537.

13. Wen XH, Lan W, Wang YX, Qian JM. Cronkhite-Canada syndrome: report of six cases and review of literature. World J Gastroenterol. 2014;20:7518-22.

14. Okamoto $\mathrm{K}$, Isomoto $\mathrm{H}$, Shikuwa $\mathrm{S}$, Nishiyama $\mathrm{H}$, Ito M, Kohno S. A case of Cronkhite-Canada syndrome:remission after treatment with anti-Helicobacter pylori regimen. Digestion. 2008;78:82-7.

15. Kato K, Ishii $Y$, Mazaki T, Uehara T, Nakamura H, Kikuchi $H$, et al. Spontaneous regression of polyposis following abdominal colectomy and Helicobacter pylori eradication for Cronkhite-Canada Syndrome. Case Rep Gastroenterol. 2013;7:140-6.

16. Berzin TM, Greenberger NJ, Levy BD, Loscalzo J. Clinical problem-solving. Worth a second look. N Engl J Med. 2012;366:463-8.

17. Watanabe-Okada E, Inazumi T, Matsukawa H, Ohyama M. Histopathological insights into hair loss in Cronkhite-Canada syndrome: diffuse anagen-telogen conversion precedes clinical hair loss progression. Australas J Dermatol. 2014;55:145-8.

18. Horikawa H, Hirai I, Umegaki-Arao N, Amagai M, Saito M. Alopecia in Cronkhite-Canada syndrome: Is it truly telogen effluvium? . Australas J Dermatol. 2019;60:e342-3.

19. Chuamanochan M, Tovanabutra N, Mahanupab P, Kongkarnka S, Chiewchanvit S. Nail Matrix Pathology in Cronkhite-Canada Syndrome: The First Case Report. Am J Dermatopathol. 2017;39:8602.

20. Yashiro M, Kobayashi H, Kubo N, Nishiguchi Y, Wakasa K, Hirakawa K. Cronkhite-Canada syndrome containing colon cancer and serrated adenoma lesions. Digestion. 2004;69:57-62.

21. Haghighi S, Noorali S, Mohammad Alizadeh AH. Cronkhite-Canada Syndrome associated with Metastatic Colon Cancer. Case Rep Gastroenterol. 2018;12:109-15.

22. Yamanouchi K, Sakata Y, Tsuruoka N, Shimoda R, Uchida M, Akutagawa T, et al. Cronkhite-Canada Syndrome complicated by triple primary cancers. Intern Med. 2016;55:1569-73.

23. Egawa T, Kubota T, Otani Y, Kurihara N, Abe S, Kimata M, et al. Surgically treated Cronkhite-Canada syndrome associated with gastric cancer. Gastric cancer. 2000;3:156-60. 
24. Nakatsubo N, Wakasa R, Kiyosaki K, Matsui K, Konishi F. Cronkhite-Canada syndrome associated with carcinoma of the sigmoid colon: report of a case. Surg Today. 1997;27:345-8.

25. Chen WQ, Li H, Sun KX, Zheng RS, Zhang SW, Zeng HM, et al. Report of Cancer Incidence and Mortality in China, 2014 (in Chinese). Chin J Oncol. 2018;40:5-13.

26. Schulte S, Kütting F, Mertens J, Kaufmann T, Drebber U, Nierhoff D, et al. Case report of patient with a Cronkhite-Canada syndrome: sustained remission after treatment with corticosteroids and mesalazine. BMC gastroenterol. 2019;19:36.

27. Cho W, Nam K, Bang KB, Shin HD, Shin JE. Cronkhite-Canada Syndrome showing good early response to steroid treatment. Korean J Gastroenterol. 2018;71:239-43.

28. Dore MP, Satta R, Murino A, Pes GM. Long-lasting remission in a case of Cronkhite-Canada syndrome. BMJ Case Rep. 2018; doi:10.1136/bcr-2017-223527.

\section{Figures}



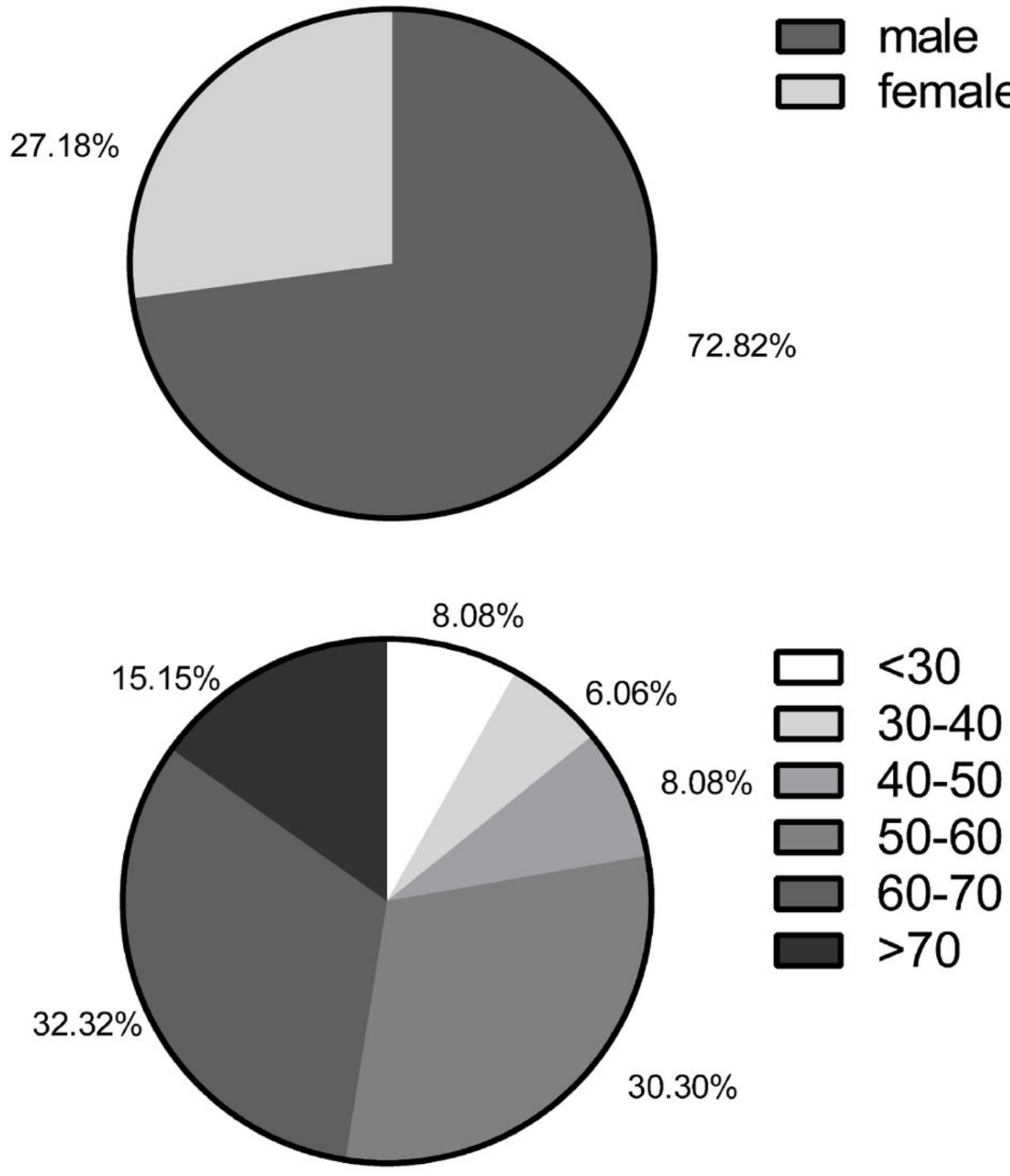

Figure 1

Sex and age distribution of Chinese Cronkhite-Canada Syndrome (CCS) patients. Fig. 1. a Of 103 Chinese CCS patients, the ratio of male to female was 2.68:1. Fig. 1. b Four patients were between 40 and 66 years old, and the effective number of age was 99 . The majority of groups were between 50 to 60 years old $₫ 30.30 \%$ \#and 60 to 70 years old (32.32\%). 

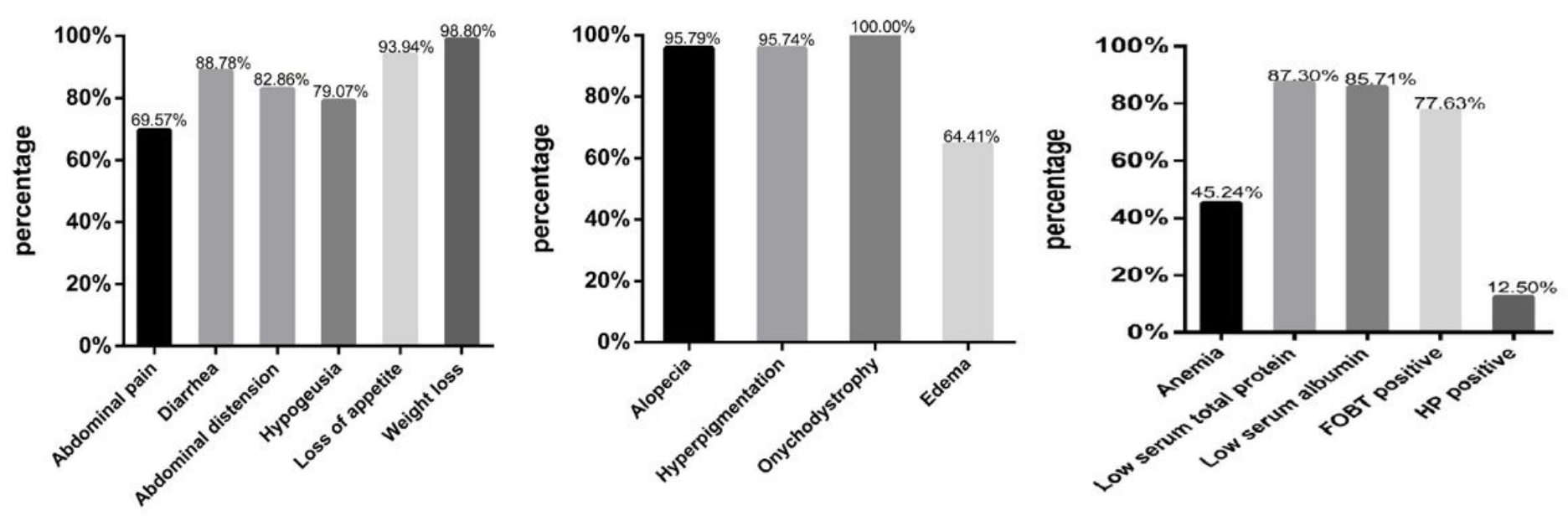

Figure 2

Clinical manifestations, physical and laboratory examinations of Cronkhite-Canada Syndrome (CCS) patients. Fig. 2. a The clinical manifestations of Chinese CCS patients were showed. and the effective number of abdominal pain, diarrhea, abdominal distension, hypogeusia, loss of appetite and weight loss was $69,98,35,43,66,83$, respectively. Fig. 2. b The physical examinations of Chinese CCS patients were observed, and the effective number of alopecia, hyperpigmentation, onchodystrophy and edema was 95 , $94,101,59$, respectively. Fig. 2. c The laboratoy examinations results of Chinese CCS patients, and the effective number of hemoglobin, serum total protein, serum albumin, fecal occult blood test (FOBT) and Helicobacter pylori (HP) test was $84,63,84,76$ and 24 , respectively. 


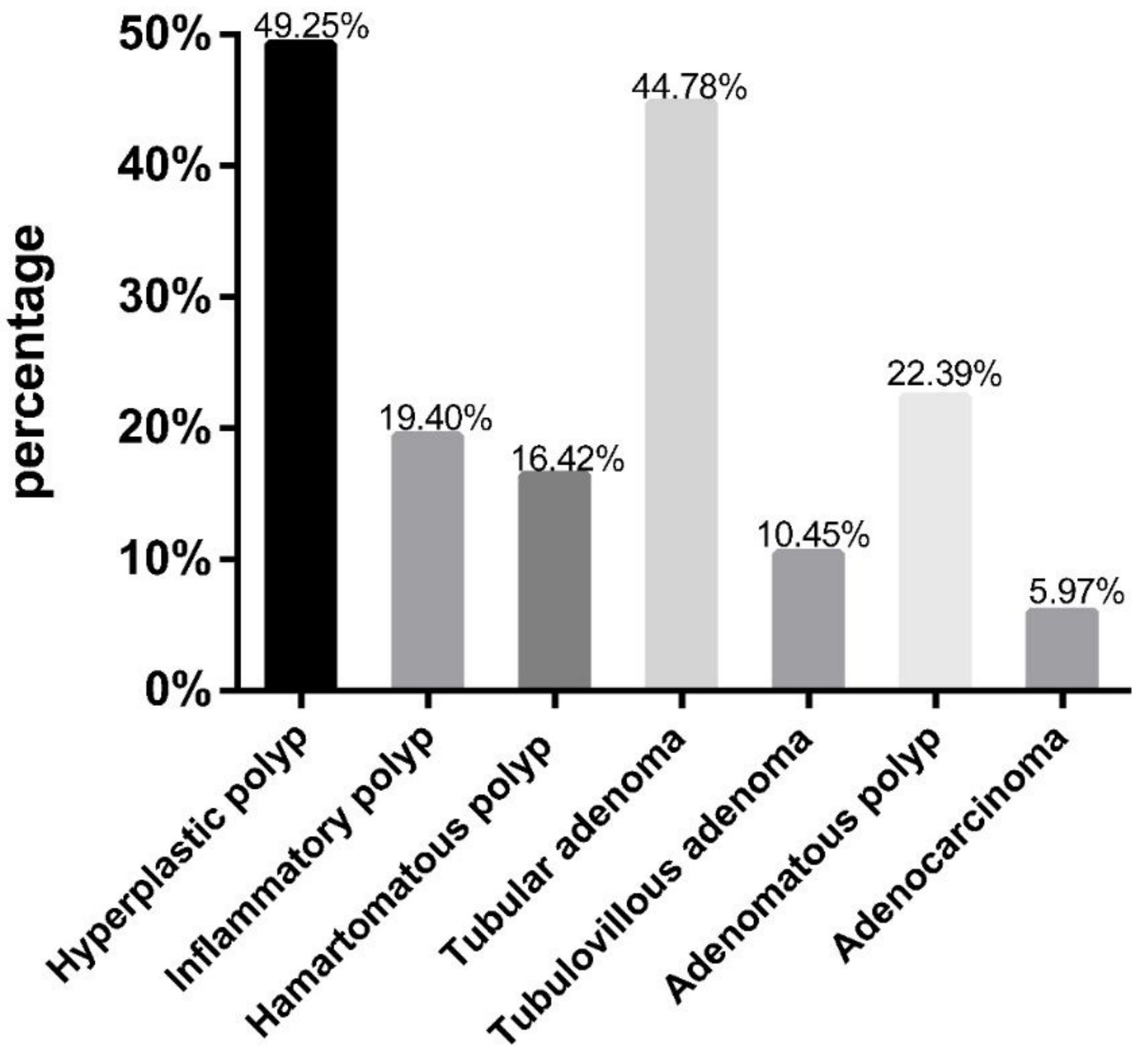

Figure 3

The pathological features of polyps in Chinese Cronkhite-Canada Syndrome (CCS) patients. The effective number of pathological features was 67 . There were 7 cases of hyperplastic polyp, 4 cases of inflammatory polyps, 2 cases of hamartomatous polyp, 8 cases of tubular adenoma, and 3 cases of adenomatous polyp without specifying the location of the lesion. Hyperplastic polyps and tubular adenomas were the most common, accounting for $49.25 \%$ and $44.78 \%$, respectively. 